\title{
Molecular diagnosis and genetic relationship of foot and mouth disease virus serotype Asia1/Basne/Sul/2015
}

\author{
J.M. Abdul Aziz ${ }^{1,3^{*}}$, S.A. Hama ${ }^{1,2}$ and H.K. Faraj ${ }^{3}$. \\ ${ }^{1}$ Medical Laboratory Science Dept, College of Health Sciences, University of Human Development, Sulaymaniyah, \\ ${ }^{2}$ Biology Department, College of Science, University of Sulaimani, Sulaymaniyah, ${ }^{3}$ Basne Veterinary Department, Molecular \\ Diagnostic Laboratory, Sulaimani Veterinary Directorate, Kurdistan Region, Iraq \\ *E-mail: jeza.muhamad@uhd.edu.iq
}

(Received May 2, 2018; Accepted July 22, 2018)

\begin{abstract}
Foot and Mouth Disease (FMD) is the most economically important viral-induced livestock disease worldwide. From April to May of 2015, tongue epithelial tissue samples were collected from 36 cattle in six villages, which share the border with Iran. Samples were screened using RT-PCR to amplify a conserved region in the VP1 gene, and phylogenetic tree analysis was performed based on the VP1 nucleotide sequence results. Furthermore, the nucleotide sequence was converted to an amino acid sequence in order to detect similarities between the studied samples and those previously published in GenBank (NCBI). Epidemically, based on the amino acid residues, genetic similarity, and amino acid substitutions, the VP1 nucleotide sequences were determined to be close to a novel group, group VII, with $94 \%$ identity. The VP1 amino acid sequence analysis revealed a close relationship to the Asia/BAL/PAK/iso-2/2011 isolate (Accession no. JX435109), with 95.7\% identity. Analysis of the studied samples revealed that the FMDV serotype Asial causing the outbreak in the Basne district belonged to group VII, which was introduced from the Balochistan province of Pakistan through illegal movement of animals from this region.
\end{abstract}

Keywords: FMD virus, serotype Asia1, Genetic relationship, VP1 Available online at http://www.vetmedmosul.com

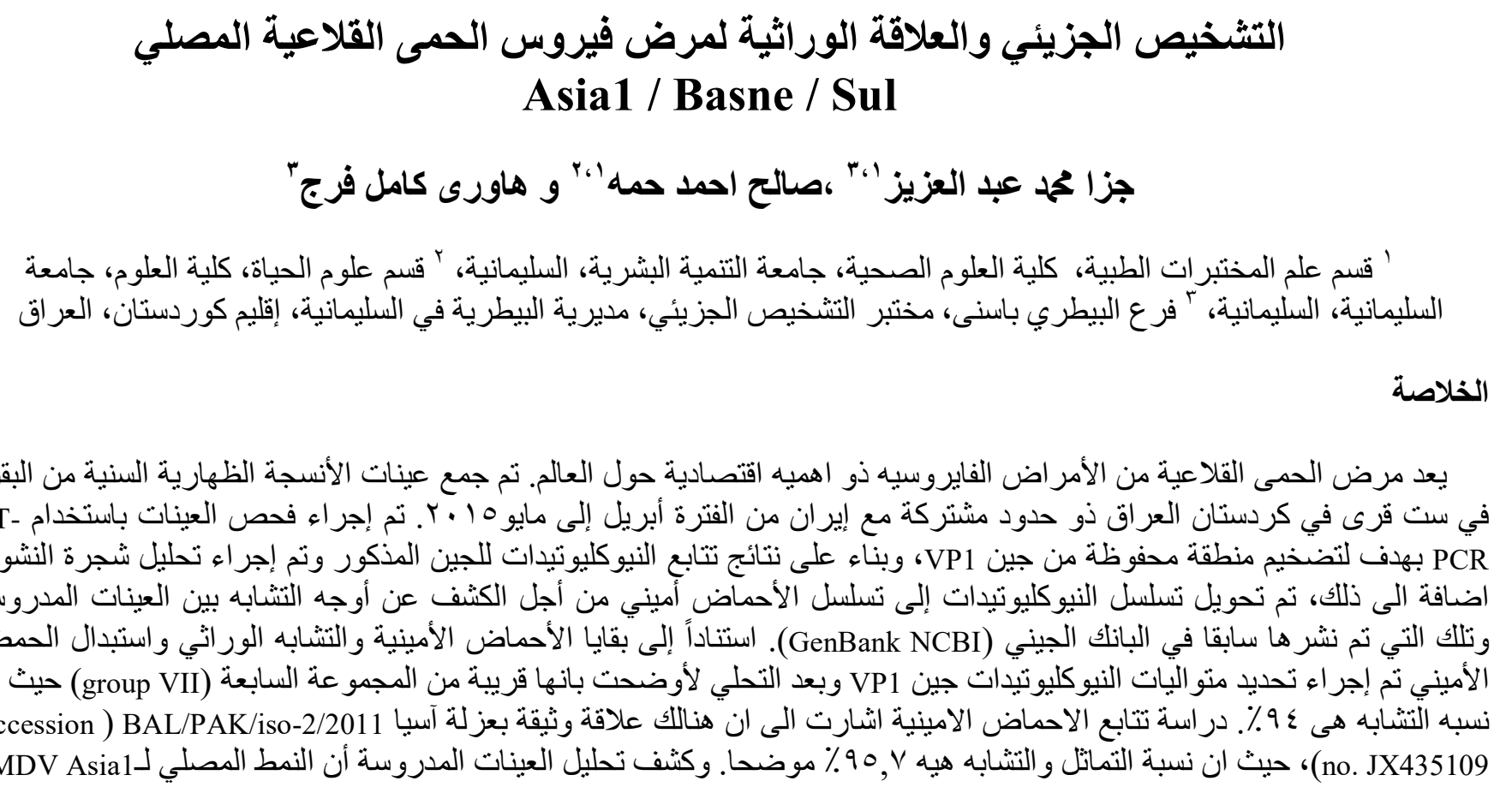




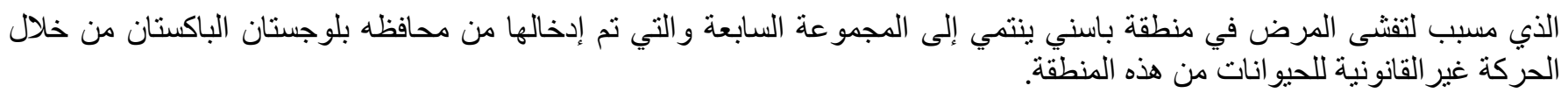

\section{Introduction}

Foot and Mouth Disease (FMD) is an acute, highly contagious transboundary viral disease of cloven-hoofed domestic animals (1). The FMD virus (FMDV) belongs to the family Picornaviridae and the genus Aphthovirus. The infection is characterized by fever, lameness, and vesicular lesions of the feet, tongue, snout, and teats. In addition to high mortality rates, the disease has a serious impact on food security, rural income, and therefore imposes significant economic consequences on any country harboring the virus $(2,3)$. The virus is non-enveloped and contains a positive-sense single-stranded RNA genome, approximately 8.3 kilobases in length. The RNA is surrounded by 60 copies of four structural proteins [VP1 (1D), VP2 (1B), VP3 (1C), and VP4 (1A)], which form a naked icosahedral capsid. The genome has three components, including the $5^{\prime}$ untranslated region (5' UTR), a long open reading frame (ORF), which is the coding region, and the $3^{\prime}$ untranslated region (3' UTR). The 5' UTR is approximately 1300 nucleotides long and consists of a 360-bp S fragment at its $5^{\prime}$ end; a 150 to 250 -bp poly(c) tract; a series of RNA pseudoknot structures; a cis-acting replication element (CRE), which is 55 nucleotides and contains a conserved motif (AAACA); and a 450-bp internal ribosome entry site (IRES), which is responsible for cap-independent initiation of viral protein synthesis (4). The virus also contains a single, long ORF encoding a polyprotein, which may generate precursors useful during the polyprotein processing. A series of precursor cleavages produces more than 14 mature proteins including the nonstructural proteins $\mathrm{L}, 2 \mathrm{~A}, 2 \mathrm{~B}, 2 \mathrm{C}, 3 \mathrm{~A}, 3 \mathrm{~B} 1,3 \mathrm{~B} 2,3 \mathrm{~B} 3$, $3 \mathrm{C}$, and $3 \mathrm{D}$ and the structural proteins $\mathrm{VP} 1, \mathrm{VP} 2, \mathrm{VP} 3$, and VP4.

Among the structural proteins, VP1, which contains the highly conserved RGD motif, is exposed on the capsid surface and plays an essential role in forming the virus particles and is considered to be highly immunogenic. Hence, the genetic similarity of the FMDV strains and the transmission between susceptible livestock populations were studied using VP1 coding sequences (5-7). Seven distinct serotypes of FMDV have been recognized; these include the Euroasiatic serotypes A, O, C, and Asial and the South African territory serotypes SAT1, SAT2, and SAT3. SAT1, SAT2, and SAT3 are usually present in Africa, Asial is restricted to Asia, and serotypes O, A, and $\mathrm{C}$ are found in Africa, Asia, South America, and occasionally, Europe (5).

The Asial FMDVs belonging to group VII (Sindh-08) and currently dominant in west Eurasia and were detected for the first time in the Sindh province of Pakistan in 2008, and later detected in Iran, Afghanistan, and Turkey (8).

FMDV affects over 100 countries around the world. Sometimes incursions occur from endemic regions into countries that are normally disease-free, and this has an enormous economic impact (9). However, epidemiological studies to identify the source of the FMD outbreaks are an essential part of disease control and provide information to help take effective measures against reintroduction (10).

To date, Iraq and Kurdistan governments have been unsuccessful in controlling transmission and eradication of FMDV. Geographically the villages of the Basne district share a border with Iran. Thus, this is one of the key places for illegal introduction of animals from Iran, Pakistan, and Afghanistan into Iraqi-Kurdistan regions, facilitating FMDV transmission.

This study, performed for the first time, focuses on the nucleotide sequence of VP1 and amino acid substitutions of FMD/Asial and uses the data to compare with FMDV sequences that were previously published in GenBank. This analysis led to the discovery of the source of the FMDV serotype Asia1, which is circulating among cattle in different villages in the Basne district.

\section{Material and methods}

\section{Study area and sample collection}

This research study was conducted from April 2, 2015, to May 26, 2015. Tongue epithelial tissue samples were collected from 36 unvaccinated cows, which clinically had blisters or vesicles on or in the nose, tongue, lips, teats, oral cavity, between the toes, and above the hooves. Lameness and reluctance to move were also found. Moreover, fever, depression, hypersalivation, loss of appetite and weight, and drop in milk production were also presented.

Basne distric include 22 Villages, which are located in the governorate of Sulaimani in the Kurdistan region north of Iraq, which shares a border with Iran. The cattle in the Basne, Bewre, Marwe, Shiwakal, Boskan and Dere villages were suspected of being infected with FMD. Collected samples were stored on dry ice to maintain virus activity and shipped to the Molecular Diagnostic Laboratory of Sulaimani Veterinary Directorate. Annually, there are two FMD outbreaks in the Basne district, first in the spring and later in fall.

\section{Sample preparation and RNA extraction}

Epithelial tissue samples $(25 \mathrm{mg})$ were transferred into a $1.5 \mathrm{ml}$ microcentrifuge tube containing $400 \mu \mathrm{l}$ of RB buffer and $4 \mu \mathrm{l}$ of $B$-mercaptoethanol. A micropestle was used to 
grind the tissue. The lysate was then sheared by through passing it through a $20-\mathrm{G}$ needle and syringe 10 times. After incubation at room temperature for three minutes, RNA was extracted from tissue samples using the (Geneaid, Korea), according to the manufacturer's instructions. The RNA was eluted in $50 \mu \mathrm{l}$ of DEPC- $\mathrm{H}_{2} \mathrm{O}$, then immediately used in reverse transcription.

\section{Reverse transcription of extracted RNA to cDNA}

First strand complementary DNA (cDNA) was synthesized from all extracted RNA samples using the AccuPower RT Premix (Bioneer, Korea), according to manufacturer's instructions. Five microliters of extracted RNA, $1 \mu \mathrm{l}$ of IF and IR primers (see below), and $13 \mu \mathrm{l}$ of RNase-free water were added to $0.2 \mathrm{ml}$ tubes and incubated at $70^{\circ} \mathrm{C}$ for $5 \mathrm{~min}$ in a thermal cycler to remove any secondary structure and then incubated at $4{ }^{\circ} \mathrm{C}$ for $5 \mathrm{~min}$. The mixture was added to lyophilized RT premix and incubated at $42^{\circ} \mathrm{C}$ for $60 \mathrm{~min}$, according to the manufacturer's instructions. The temperature was then elevated to $95^{\circ} \mathrm{C}$ for 5 minutes to inactivate the reverse transcriptase.

\section{Oligonucleotide primers}

Two sets of primers, which amplify conserved regions of the virus, were synthesized by Bioneer and used for general FMDV detection and serotype detection in outbreak specimens. The first primer set was universal primers that detect FMD: (IF 5'-GACATGTCCTCCTGCATCTG-3') and (IR 5'-CCAGTCCCCTTCTCAGATC-3'). The above primer set amplifies a 328-bp cDNA fragment within the untranslated region (5' UTR) of any FMDV serotype (11). The second, more specific primer set amplifies a cDNA fragment within the coding sequences of VP1, a conserved region of the FMDV genome. Another primer pairs set ((P38F 5'-GCTGCCTACCTCCTTCAA-3') and (NK61R 5'-GACATGTCCTCCTGCATCTG-3')) was designed for specific diagnosis of serotype $\mathrm{O}$, by amplifying a cDNA fragment of approximately $290 \mathrm{bp}$, within the VP1 sequence (12).

Primers (p87: 5'-GTCATTGACCTCATGCAGAC(C/T) CAC-3') and (NK61: 5'-GACATGTCCTCCTGCATCTG$3^{\prime}$ ) were designed to detect serotype A by amplifying a 613bp cDNA fragment within the VP1 sequence (12). As11 C505F primer (5'-TACACTGCTTCTGACGTGGC-3') and the universal reverse primer, NK61, were used to detect Asial serotypes by amplifying a 911-bp cDNA fragment (13). All of the primers were synthesized by Bioneer, according to the references.

\section{Uniplex PCR}

Following the first strand cDNA synthesis, the uniplex PCR was performed in $0.2 \mathrm{ml}$ tubes to detect the FMDV by employing a universal primer (IF, IR) using the AccuPower
PCR Premix (Bioneer). Five microliters of cDNA template, $1 \mu \mathrm{l}$ of each universal primer (IF, IR), and $13 \mu \mathrm{l}$ of DEPC$\mathrm{H}_{2} \mathrm{O}$ were added to the lyophilized master mix. After initial confirmation of the FMDV, the uniplex RT-PCR reaction was performed to detect three virus serotypes $(\mathrm{O} / \mathrm{A} / \mathrm{Asia} 1)$. During this study, $1 \mu \mathrm{l}$ of specific forward primer and $1 \mu \mathrm{l}$ of universal primer, NK61, were used. The PCR reaction mixture for both steps was subjected to one cycle at $94^{\circ} \mathrm{C}$ for 2 minutes, followed by 35 cycles of denaturation at $94^{\circ} \mathrm{C}$ for $30 \mathrm{~s}$, annealing at $55^{\circ} \mathrm{C}$ for $30 \mathrm{~s}$, and extension at $72^{\circ} \mathrm{C}$ for $5 \mathrm{~min}$. A final extension step of one cycle at $72^{\circ} \mathrm{C}$ for 5 min was performed.

\section{Gel analysis of RT-PCR amplification products}

Eight microliters of the RT-PCR cDNA amplicon was analyzed by mixing it with $2 \mu 1$ of loading dye in a $0.2 \mathrm{ml}$ microfuge tube and then loading on a $1 \%$ agarose gel. A 100-bp DNA ladder was loaded on the agarose gel to identify the PCR product size. The agarose gel was run in 1X TBE buffer (89 mM Boric Acid, 2 mM EDTA, pH 8.3) at $90 \mathrm{~V}$ for $60 \mathrm{~min}$. The results were visualized under UV light and were recorded by a gel documentation system.

\section{Sequencing the PCR products}

In order to confirm the PCR results, $25 \mu \mathrm{l}$ of PCR product of one sample positive with the NK72 and As1$1 \mathrm{C} 505 \mathrm{~F}$ primers were sent for Sanger sequencing (Macrogen, Seoul, South Korea). The result was published in GenBank (NCBI) as Asia1/Basne/Sul/2015, with accession number KT861787. The name is based on the serotype, district; three letter provinces code (Sul), and the sampling year.

\section{Computer analysis of genetic relationships}

The partial VP1 nucleotide sequence of the FMD Asia1/Basne/Sul/2015 isolate (Accession no. KT861787) was aligned and compared with FMD/Asial from other countries, which were previously published in the GenBank database (Fig. 1). The ClustalW algorithm in BioEdit software version.7.2.5 was used and sequences were edited to remove unreliable sequences or regions (14). Phylogenetic tree analysis was performed based on the nucleotide sequences (Fig. 2) using MEGA 6.0.6 and the unweighted pair group with arithmetic mean (UWPGM) method with the Evolutionary distances were computed by using Kimura 2-parameter substitution model and are in the units of the number of nucleotide substitutions per site. The robustness of the tree topology was assessed with 1,000 bootstrap replicates, as implemented within the program, and the gaps or missing data were treated with pairwise deletions (15). and remaining data was divided into four groups. The nucleotide sequences were translated into amino acid sequences to discover any amino acid substitutions. Moreover, similarity percentages among 17 sequences were obtained in the BioEdit 6.0.6 software (14). 


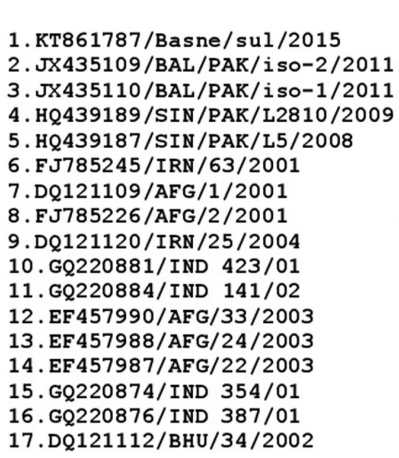

1. KT861787/Basne/sul/2015 2. JX435109/BAL/PAK/i so-2/2011

3. JX435110/BAL/PAK/i so- $1 / 2011$ 5. HQ439187/SIN/PAK/L5/2008

6.FJ785245/IRN/63/2001

7.DQ121109/AFG/1/2001

3. EF 457988/AFG/24/2003

16. GQ220876/IND 387/01

17. DQ121112/BHU/34/2002

1. KT861787/Basne/sul/2015 2. JX435109/BAL/PAK/i so-2/2011 3. JX435110/BAL/PAK/i so- $1 / 2011$ 4. HQ439189/SIN/PAK/L2810/2009 5. HQ439187/SIN/PAK/L5/2008

6. FU785245/IRN/63/2001

7. DQ121109/AFG/1/2001

8. FJ785226/AFG/2/2001

9. DQ121120/IRN/25/2004

10. GQ220881/IND 423/01

11. GQ220884/IND $141 / 02$

12. EF $457990 /$ AFG $/ 33 / 2003$

13. EF457988/AFG/24/2003

14. EF $457987 /$ AFG/22/2003

15. GQ220874/IND 354/01

16. GQ220876/IND 387/01

17. DQ121112/BHU/34/2002

$\begin{array}{lrrrrrrrr}10 & 20 & 30 & 40 & 50 & 60 & 70 & 80 & 90 \\ \cdots & 20 & 30 & 100\end{array}$ . W .

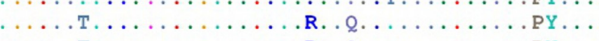

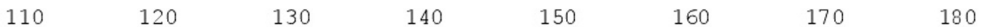

$\ldots|\ldots| \ldots|\ldots| \ldots|\ldots| \ldots|\ldots| \ldots|\ldots| \ldots|\ldots| \ldots|\ldots| \ldots|\ldots| \ldots|\ldots| \ldots|\ldots| \ldots \mid \ldots$ LP YTAPHRVLATVYNGKTVY GSEAPRRGDLAAVAQRVST SLPTSF NY GAVKAENI TELLI RMKRAETYCPRPLLALDTTQNHRKQEI

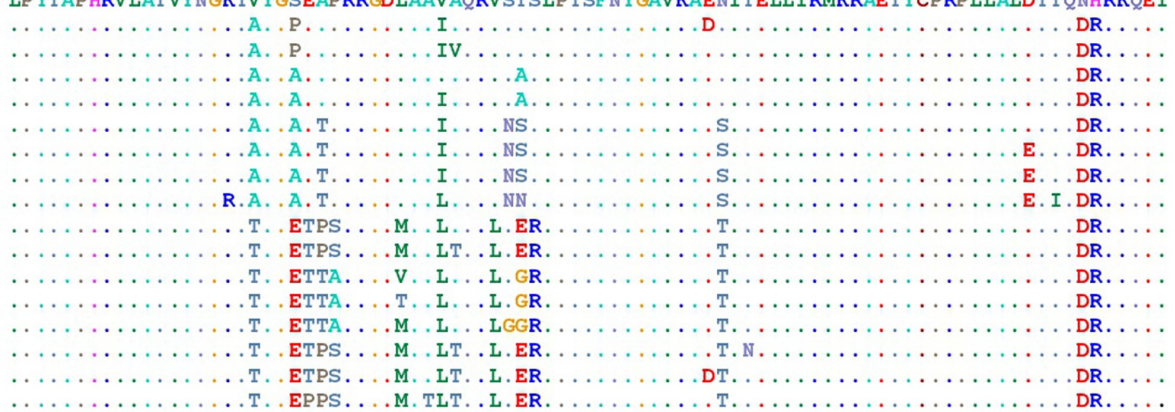

Figure 1: Alignment of amino acid sequence of partial VP1 FMDV serotype Asia-1 from Basne with other Amino acid sequences showing difference (similarities shown as dot).

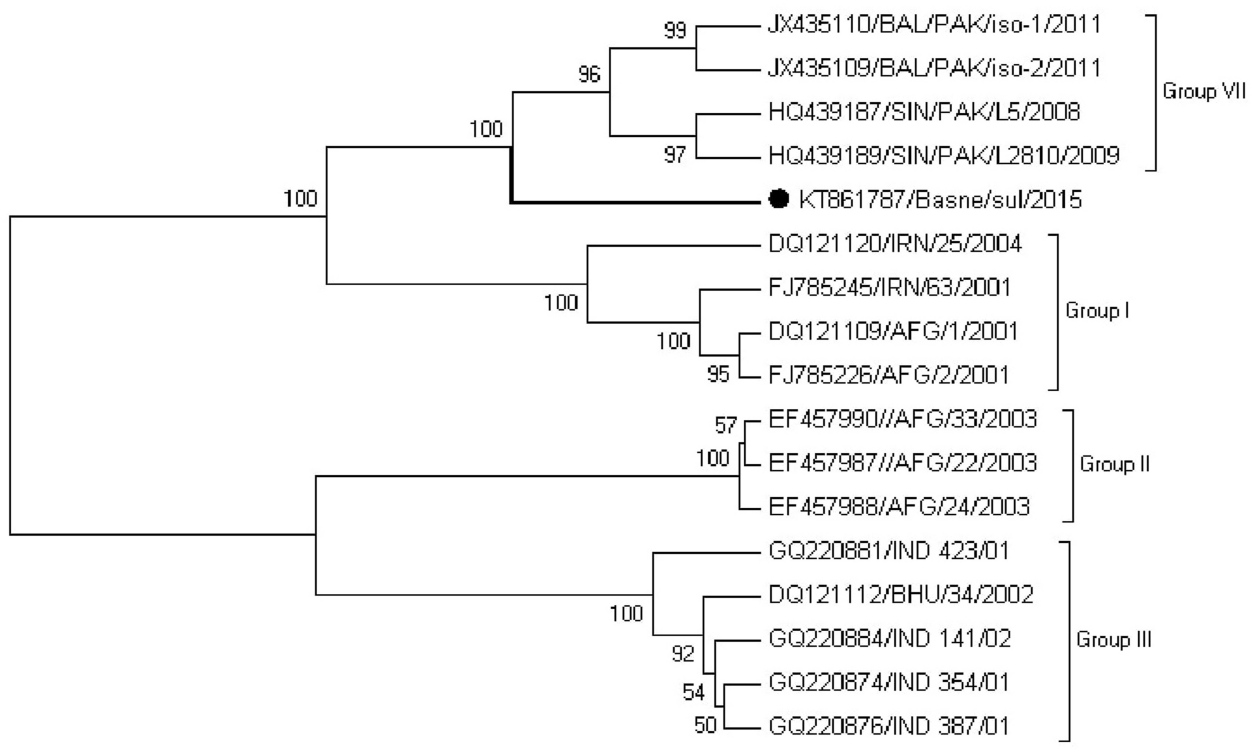

Figure 2. Phylogenetic tree based on the Nucleotide sequencing VP1 of FMD/Asia1/ recent outbreak in Basne district of Sulaimani province, which is showed relationships with the other isolate sequences were retrieved from GenBank/database. 


\section{Results}

The collected samples were tested by RT-PCR, which was performed in two steps. First, RT-PCR amplification of the conserved region in the $5^{\prime}$ UTR was performed using a universal primer set (IF and IR). A positive result was observed for all FMDV serotypes, in which a 328-bp band was detected (11). In the second step, a uniplex PCR was used with primers to detect FMDV serotypes $(\mathrm{O}, \mathrm{A}$, and Asia1). The amplicon was confirmed by agarose gel electrophoresis, where a single 911-bp band was detected, revealing that the primer (As1 1C-505/NK61) specific for Asia1 amplified the correct size VP1 product. No amplicon band appeared with the other primer sets, which were specific for serotypes $\mathrm{O}$ and A. The results of uniplex PCR showed that the serotype Asia1, was the causative agent for FMD that circulated in the villages of the Basne district.

\section{Phylogenetic tree and sequence analysis}

Based on the VP1 gene sequence, a phylogenetic tree was constructed to clarify the genetic relationship of isolated FMDV serotype Asial with the FMDV strains from Pakistan, Afghanistan, Iran, India, and Bhutan (Fig. 2 ). The Phylogenetic tree revealed genetic relationships, showing that the Basne/Sul/2015 isolate circulating in the Basne district was closely related to the group VII virus, which fell into four lineages isolated in Balochistan (2011) and Sindh (2008-2009) in Pakistan. Members of this group, which had been isolated four to seven years earlier, had
$97 \%$ to $99 \%$ nucleotide identity with the viruses in this study.

The partial VP1 amino acid sequences of the Basne/Sul/2015 isolate were compared with the 16 sequences previously published in the GenBank and showed 38 variable amino acids and (8-24) amino acid substitutions with all obtained virus sequences (Fig. 2).

The eight and ten amino acid substitutions of the Basne isolates were S42P, H43Y, V119A, S122P, V133I, E153D, N181D, H182R, and sequences were compared with the JX435109/BAL/PAK/iso-2/2011 isolate. Sequences A31T and A134V were compared with the JX435110/BAL/PAK/iso-1/2011 isolate. In addition, samples with 10 and 11 amino acid substitutions included the following substitutions: A9T, K25R, N28Q, S43P, H44Y, V119A, S122A, T139A, N181D, and H182R, and were compared with the HQ439189/SIN/PAK/L2810/2009 isolate. Those with the V133I substitution were compared with the HQ439187/SIN/PAK/L5/2008 isolate, within group VII. Further, samples showed higher numbers of 24 amino acid residues shared with the JX435109/BAL/PAK/iso-2/2011 isolate (Fig. 1) compared to other viruses in Group VII and these shared amino acids include $1 \mathrm{~N}, 8 \mathrm{~A}, 17 \mathrm{G}, 20 \mathrm{~L}, 25 \mathrm{~K}, 27 \mathrm{~T}, 28 \mathrm{~N}, 31 \mathrm{~A}, 64 \mathrm{~L}, 70 \mathrm{~V}$, 77A, 80T, 84C, 92I, 107K, 123E, 124A, 130L, 132A, $137 \mathrm{~V}, 138 \mathrm{~S}, 139 \mathrm{~T}, 140 \mathrm{~S}, 154 \mathrm{~N}, 155 \mathrm{I}, 156 \mathrm{~T}, 177 \mathrm{D}$ and 178T. On the other hand, amino acid homology percentages in the identity matrix for all groups (Table. 1) were from $95.7 \%$ to $87.1 \%$.

Table 1: Amino acid sequence identity (\%) of Asia1/ Basne/Sul/2015 compared with the other viruses (bold show highest identities). Identities percent generated by Bioedit software version.7.2.5.

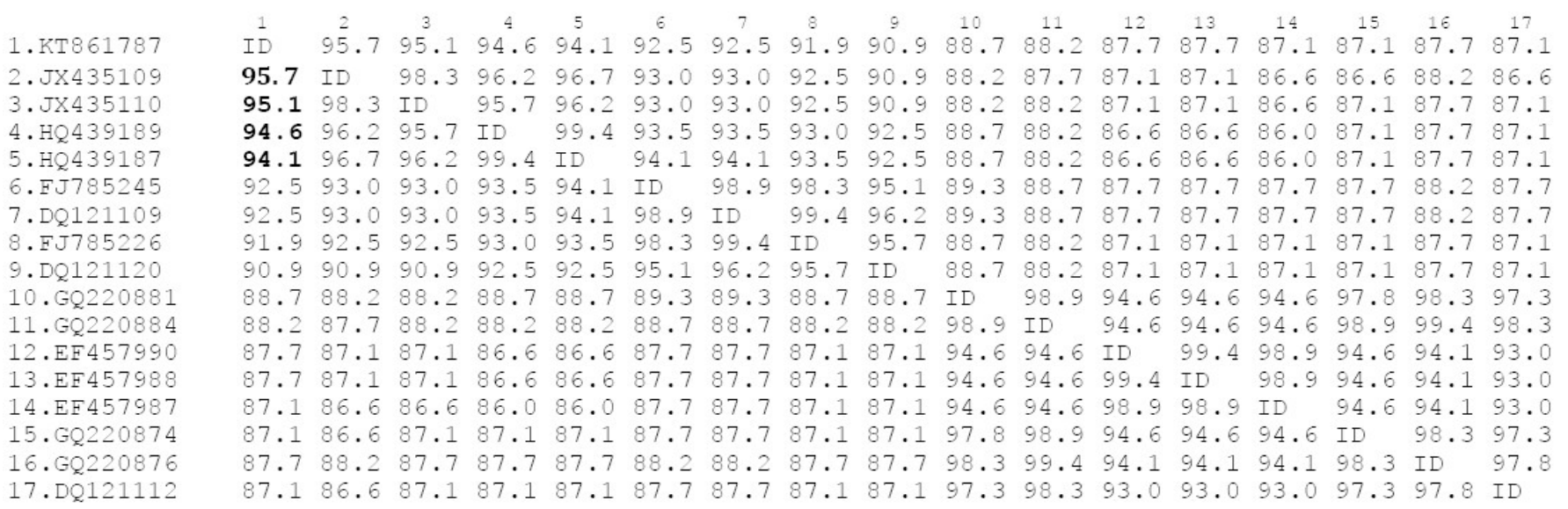

In the current study, it was noticed that the Basne/Sul/2015 isolate had eight amino acid substitutions (Fig. 1) and showed higher similarity (95.7\%) to the group VII cluster (JX435109/BAL/PAK/iso-2/2011) circulating in the Balochistan province of Pakistan in 2011. Therefore, according to the nucleotide and amino acid sequence analysis, the Asia1/FMD/Basne/Sul/2015 virus isolated in the Basne district showed the highest similarity with group VII, particularly with JX435109/BAL/PAK/iso-2/2011 isolate, which was from clinically diseased animals in Balochistan, Pakistan. 


\section{Discussion}

Early diagnosis of FMDV is a vital tool for disease control and it has been established that quick control of FMD is the foremost way to reduce dissemination of the causative virus to other non-infected regions $(16,17)$. In this study, uniplex RT-PCR was used to diagnose FMDV using the generic reverse and forward primers (IF/IR) which recognize a highly conserved region in the $5^{\prime}$ UTR of the FMDV. Reid et al. (11) in the UK, previously found the IF/IR set was sensitive in RT-PCR in the primary diagnosis of FMD. However, IF/IR primers cannot be used to identify specific serotypes $(\mathrm{O}, \mathrm{A}, \mathrm{C}$, and Asial) since the 5' UTR does not contain serotype-specific information. The nested RT-PCR was an additional improvement in the primary diagnosis of FMD (18). allowing for the successful detection of the Asial serotype, which is consistent with previously reported results using the same primer set (13).

During this study, the conserved region of the VP1 gene from the FMDV was used for detecting different serotypes. This region of the gene has the most variable regions among the capsid polypeptide sequences. Conventional RTPCR was successful for amplification in this region. Moreover, VP1 contains important immunogenic sites, including amino acid residues within the G-H loop and the $\mathrm{C}$-terminus. The G-H loop includes an arginine-glycineaspartic acid (RGD) motif that is necessary for attachment of the virus to integrin receptors on the host cell $(19,20)$. Phylogenetic analyses based on the VP1 nucleotide sequence have been used widely to deduce evolutionary dynamics, understand genetic relationships among the genetic lineages, and trace the origin and movement of outbreak strains $(21,22)$. Additionally, researchers have used the VP1 coding sequence for molecular epidemiology in an effort to determine the origin of the Asial serotype outbreaks circulating in Pakistan, Afghanistan, Tajikistan, Kyrgyzstan, and Hong Kong $(11,23,24)$.

Using BLAST in NCBI, the VP1 nucleotide sequence of the Asial FMDV serotype responsible for FMD outbreaks in the Basne district in 2015 were compared with other isolates in GenBank, indicating that the virus in this study was closely related to the following isolates: Asia/BAL/PAK/sio-1/2011, Asia/BAL/PAK/sio-2/2011, Asia/SIN/PAK/L2954/2009, and Asia/SIN/PAK/L2810/2009. Their overall sequence identity was $94 \%$ and this close relationship was confirmed by phylogenetic tree analysis, as shown in (Fig. 1). Surprisingly, the isolated FMDV from outbreaks in the Basne district genetically belonged to a novel group, group VII, which had been detected for the first time in the Sindh province of Pakistan in 2008-2009 and was later identified in Afghanistan, Turkey, Iran, and west Eurasian regions (8).

For additional confirmation, the partial amino acid sequence of VP1 was used for analysis and revealed that the FMDV in the Basne district was closely related to the Asia/BAL/PAK/sio-2/2011 isolate (Accession no. JX435109), which was responsible for the FMDV outbreak in the Balochistan province in Pakistan in 2011. It was determined that the sequence identity between the two was 95.7\%, as shown in Table 1, and there was an even greater similarity between the two at the amino acid level. This finding suggested that the Asial FMDV circulating in Basne, epidemically originated in Pakistan, although this strain has been reported previously in the middle east (25). The isolates of FMDV serotype Asial were collected from 2003 to 2007 from several Asian countries and were classified into six groups, I-VI, based on the nucleotide divergence, with a $5 \%$ cut-off (26). Later, Jamal et al (9). identified a novel group, group VII, from Pakistan, which was collected from 2008 to 2009.

\section{Conclusion}

This study revealed that the FMDV serotype Asial circulating in the Basne district genetically belonged to the group VII, which was imported into this region from the Balochistan province in Pakistan. Furthermore, using of an appropriate vaccine, such as that for group VII strains in this case, is critical. However, further studies will be required to confirm these findings.

\section{Acknowledgement}

I would like to thanks, Sulaimani Veterinary Directorate for providing laboratory facilities and many thanks to Dr. Muhamed Omer and Dr. Peshnyar Rashid for their technical contribution.

\section{Competing interests}

The authors report no conflicts of interest in this work.

\section{Ethical approval}

This research study does not contain any studies with human participants or experimental animals performed by authors.

\section{Funding}

This research did not receive any specific grant from funding agencies in the public, commercial, or not-forprofit sectors.

\section{Contributorship statement}

Jeza Muhamad Abdul Aziz "Conception and design, Acquisition of data, Analysis, and interpretation of data. 
Salih Ahmed Hama "Drafting the article, Critical revision of the article". Hawre Kamel Faraj "Final approval of the version to be published".

\section{References}

1. Elhaig MM, Elsheery MN. Molecular investigation of foot-and-mouth disease virus in domestic bovids from Gharbia, Egypt. Trop Anim Health Prod. 2014;46(8):1455-62.

2. Arzt J, Juleff N, Zhang Z, Rodriguez LL. The Pathogenesis of Foot - and - Mouth Disease I: Viral Pathways in Cattle. Transbound Emerg Dis. 2011;58(4):291-304.

3. Di Nardo A, Knowles NJ, Paton DJ. Combining livestock trade patterns with phylogenetics to help understand the spread of foot and mouth disease in sub-Saharan Africa, the Middle East and Southeast Asia. Rev Sci Tech. 2011;30(1):63.

4. Jamal SM, Ferrari G, Ahmed S, Normann P, Belsham GJ. Genetic diversity of foot-and-mouth disease virus serotype $\mathrm{O}$ in Pakistan and Afghanistan,1997-2009. Infect Genet Evol. 2011;11(6):1229-38.

5. Knowles NJ, Samuel AR. Molecular epidemiology of foot-and-mouth disease virus. Virus Res. 2003;91(1):65-80.

6. Zinnah MA, Islam MT, Rahman MM, Hossain MT, Bari MR, Haque MH, Khan MS, Islam MA. Standardization of multiplex reverse transcription-polymerase chain reaction and typing of foot-and-mouth disease virus prevalent in Bangladesh. Bangladesh $\mathrm{J}$ Vet Med. 2012;8(2):149-55.

7. Subramaniam S, Mohapatra JK, Sharma GK, Das B, Dash BB, Sanyal A, Pattnaik B. Phylogeny and genetic diversity of foot and mouth disease virus serotype Asial in India during 1964-2012. Vet Microbiol. 2013;167(3):280-8.

8. Jamal SM, Ferrari G, Ahmed S, Normann P, Belsham GJ. Molecular characterization of serotype Asia-1 foot-and-mouth disease viruses in Pakistan and Afghanistan; emergence of a new genetic Group and evidence for a novel recombinant virus. Infect, Gen Evol. 2011;31;11(8):2049-62.

9. Jamal SM, Belsham GJ. Foot-and-mouth disease: past, present and future. Vet Rec. 2013;44(1):116.

10. Jin-Ho SH, Hyun-Joo SO, Byung-Jun KW, Young-Joon KO, DongJun AN, Sang-Ho CH, Jong-Hyeon PA, JEONG WS, Jee-Yong PA, KWEON CH, Jae-Young SO. Molecular epidemiological investigation of foot-and-mouth disease virus in Korea in 2000. J Vet Med Sci. 2003;65(1):9-16.

11. Reid SM, Ferris NP, Hutchings GH, Samuel AR, Knowles NJ. Primary diagnosis of foot-and-mouth disease by reverse transcription polymerase chain reaction. J Virol Meth. 2000;89(1):167-76.

12. Reid SM, Ferris NP, Hutchings GH, De Clercq K, Newman BJ, Knowles NJ, Samuel AR. Diagnosis of foot-and-mouth disease by RT-PCR: use of phylogenetic data to evaluate primers for the typing of viral RNA in clinical samples. Arch Virol. 2001;146(12):2421-34.

13. Al-Rodhan AM, Salem ZM. Molecular and serological Identification of foot and mouth disease Virus serotypes in cattle of Basrah Province. Basrah J Vet Res. 2014;1(1):180-197.
14. BioEdit: a user-friendly biological sequence alignment editor and analysis program for Windows 95/98/NT. Nucl Acid Symp Ser. 1999:41:95-98.

15. Tamura K, Stecher G, Peterson D, Filipski A, Kumar S. MEGA6: molecular evolutionary genetics analysis version 6.0. Mol Biol Evol. 2013;30(12):2725-29.

16. Howard SC, Donnelly CA. The importance of immediate destruction in epidemics of foot and mouth disease. Res Vet Sci. 2000 ;69(2):18996.

17. Knowles NJ, Samuel AR, Davies PR, Kitching RP, Donaldson AI. Outbreak of foot-and-mouth disease virus serotype $\mathrm{O}$ in the UK caused by a pandemic strain. Vet Rec. 2001;148(9):258.

18. Moss A, Haas B. Comparison of the plaque test and reverse transcription nested PCR for the detection of FMDV in nasal swabs and probang samples. J Virol Meth. 1999;80(1):59-67.

19. Fox G, Parry NR, Barnett PV, McGinn B, Rowlands DJ, Brown F. The cell attachment site on foot-and-mouth disease virus includes the amino acid sequence RGD (arginine-glycine-aspartic acid). J Gen Virol. 1989;70(3):625-37.

20. Jackson T, Sharma A, Ghazaleh RA, Blakemore WE, Ellard FM, Simmons DL, Newman JW, Stuart DI, King AM. Arginine-glycineaspartic acid-specific binding by foot-and-mouth disease viruses to the purified integrin alpha (v) beta3 in vitro. J Virol. 1997;71(11):835761.

21. Vangrysperre W, De Clercq K. Rapid and sensitive polymerase chain reaction-based detection and typing of foot-and-mouth disease virus in clinical samples and cell culture isolates, combined with a simultaneous differentiation with other genomically and/or symptomatically related viruses. Arch Virol. 1996;141(2):331-44.

22. Valdazo-González B, Polihronova L, Alexandrov T, Normann P, Knowles NJ, Hammond JM, Georgiev GK, Özyörük F, Sumption KJ, Belsham GJ, King DP. Reconstruction of the transmission history of RNA virus outbreaks using full genome sequences: foot-and-mouth disease virus in Bulgaria in 2011. PLoS one. 2012;7(11):e49650.

23. Jamal SM, Ferrari G, Hussain M, Nawroz AH, Aslami AA, Khan E, Murvatulloev S, Ahmed S, Belsham GJ. Detection and genetic characterization of foot - and - mouth disease viruses in samples from clinically healthy animals in endemic settings. Transbound Emerg Dis. 2012;59(5):429-40

24. Samuel AR, Knowles NJ. Foot-and-mouth disease type O viruses exhibit genetically and geographically distinct evolutionary lineages (topotypes). J Gen Virol. 2001;82(3):609-21.

25. Genotyping report FMDV type Asia-1. WRL-FMD. (2012). www.wrlfmd.org/fmd_genotyping/middle_east.

26. Valarcher JF, Knowles NJ, Zakharov V, Scherbakov A, Zhang Z, Shang YJ, Liu ZX, Liu XT, Sanyal A, Hemadri D, Tosh C, Rasool TJ, Pattnaik B, Schumann KR, Beckham TR, Linchongsubongkoch W, ferris NP, Roeder PL, Paton DJ. Multiple origins of foot-and-mouth disease virus serotype Asia 1 outbreaks, 2003-2007. Emerg Infect Dis. 2009;15:1046-1051. 